\title{
Editorial for Special Issue "Remote Sensing Water Cycle: Theory, Sensors, Data, and Applications"
}

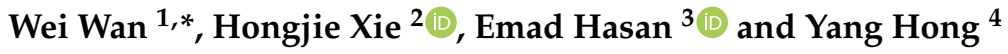 \\ 1 Institute of Remote Sensing and GIS, School of Earth and Space Sciences, Peking University, \\ Beijing 100871, China \\ 2 Department of Geological Sciences, University of Texas at San Antonio, San Antonio, TX 78249, USA; \\ Hongjie.Xie@utsa.edu \\ 3 Department of Geography, State University of New York (SUNY) at Binghamton, \\ Binghamton, NY 13902, USA; emad.hasan@ou.edu \\ 4 School of Civil Engineering and Environmental Science, University of Oklahoma, Norman, OK 73019, USA; \\ yanghong@ou.edu \\ * Correspondence: w.wan@pku.edu.cn
}

Received: 16 May 2019; Accepted: 21 May 2019; Published: 22 May 2019

\section{Introduction}

Global water cycle dynamics involve the exchange of water and energy matter among the atmosphere, hydrosphere, geosphere, cryosphere, and biosphere. Remote sensing provides a unique advantage of observing and acquiring complex water cycle and hydrological state variables across a wide range of spatial and temporal scales. The recent advances in remote sensing technology and numerical hydrological models alleviate our ability to observe and predict the storage, fluxes, and movement of water in time and space. Remote sensing offers unprecedented opportunities to gain a better and comprehensive understanding and mapping of water distribution and variability, in response to climate change and human activities. Besides, remote sensing data enables global and regional hydrological applications, and water resources management, motivates new theories in mapping applications and offers new ways to predict and resolve global water resources conflicts. This Special Issue encompasses a number of contributions in satellite and airborne sensors applications in hydrology, including: mapping theories and applications, i.e., [1-3], new methods to better observe hydrological component, i.e., precipitation [4,5], precipitable water vapor (PWV) and vapor pressure deficit (VPD) [6-8], energy fluxes and evapotranspiration [9], and snowfall [10], and new methods to improve hydrological decision support system, i.e., [11]. The following section briefs the overall contributions in this Special Issue.

\section{Overview of Contributions}

This special issue has three papers related to mapping theories and applications in remote sensing water cycle. Canisius et al. [1] evaluated the application of SAR Backscatter and InSAR coherence to monitor the wetland extent across Amazon lowland. In their research, the authors showed that wetland vegetation types were successfully classified with $86 \%$ accuracy, using the statistical parameters derived from the multi-temporal intensity and coherence RADARSAT-2 data stacks. Wang et al. [2] used eight years of Odin/SMR retrievals to account the Stable Water Isotopologues (SWIs) in the stratosphere layer, and they also analyzed the spatial and seasonal characteristics of the SWIs. Wan et al. [3] monitored the flood inundation in China during typhoon and extreme precipitation events in 2017, using the Cyclone Global Navigation Satellite System (CYCNSS) data. CYGNSS is a newly launched small satellite constellation designed to measure ocean surface wind speed in hurricanes and tropical cyclones. 
The concept of this paper is innovative since it explores the additional capabilities of CYGNSS for applications of land surface hydrology.

This special issue contains two papers related to precipitation estimates, using remote sensing data. He et al. [4] and Ma et al. [5] both developed new methods to derive downscaled precipitation estimates over the Tibetan Plateau. Long-term, fine spatial resolution and good-quality precipitation data sets over the Tibetan Plateau are difficult to acquire due to its harsh environment. In their research, He et al. [4] provided a new retrospective framework to downscale precipitation estimates based on the Tropical Rainfall Measuring Mission (TRMM) Multi-Satellite Precipitation Analysis (TMPA) data products and ground observations. The methods of this paper show the potential to obtaining retrogressive precipitation estimates, dating back to 1990s; Ma et al. [5] compared the downscaled TMPA and Integrated Multi-satellitE Retrievals for Global Precipitation Measurement (IMERG) products, and they also developed methods to derive annual and monthly precipitation estimates.

Besides, this special issue encompasses three papers related to water vapor estimates using satellite data. Trent et al. [6] observed the water vapor in the Planetary Boundary layer (PBL) using short-wave infrared observations from Japanese space agency (JAXA)'s Greenhouse Gases Observing SATellite (GOSAT); this is the first satellite single-sensor estimates of bulk PBL water vapor over land and (sunglint) ocean. Zhang et al. [7] developed a new model to acquire the PWV estimates, using GPS observations in tropical areas. Du et al. [8] proposed a unique approach to estimate the vapor pressure deficit using the AMSR-E and AMSR2 satellite observations.

Further, this special issue encloses two papers addressing other hydrological components, i.e., evapotranspiration and snowfall. Silva Oliveira et al. [9] advanced the albedo estimates for modeling energy-balance fluxes and evapotranspiration over agricultural and natural areas in Brazilian Cerrado; Panegrossi et al. [10] utilized the CloudSat-based observation to assess the Global Precipitation Measurement (GPM)'s microwave ability to observe snowfall.

As for involving remote sensing data to improve hydrological decision support system, Mohamed et al. [11] presented a case study about utilizing satellite-based precipitation observations to enhance the decision support system for water resource management in Lowe Mekong River Basin. This study demonstrated impressive applications in using satellite remote sensing data to pursue hydrologic modeling in regions with scarce or inaccessible in-situ precipitation observations.

\section{Conclusions}

Remote sensing has a unique advantage of acquiring complex water cycle information continuously in time and space; this makes "Remote Sensing Water Cycle" an emerging topic in recent years. The contributions of this Special Issue successfully addressed grand challenges of the water cycle research field: the methods and sensors to observe and predict the storage, fluxes, and movement of water across a range of space-time scales by integrating advanced remote sensing technology and numerical water models into a theory-data-application end-to-end framework.

Author Contributions: All co-authors contributed equally to all aspects of this editorial.

Acknowledgments: The authors of this Editorial would like to thank the authors who contributed to this Special Issue and to the reviewers who provided valuable and constructive review comments.

Conflicts of Interest: The authors declare no conflict of interest.

\section{References}

1. Canisius, F.; Brisco, B.; Murnaghan, K.; Van Der Kooij, M.; Keizer, E. SAR Backscatter and InSAR Coherence for Monitoring Wetland Extent, Flood Pulse and Vegetation: A Study of the Amazon Lowland. Remote Sens. 2019, 11, 720. [CrossRef]

2. Wang, T.; Zhang, Q.; Lossow, S.; Chafik, L.; Risi, C.; Murtagh, D.; Hannachi, A. Stable Water Isotopologues in the Stratosphere Retrieved from Odin/SMR Measurements. Remote Sens. 2018, 10, 166. [CrossRef] 
3. Wan, W.; Liu, B.; Zeng, Z.; Chen, X.; Wu, G.; Xu, L.; Chen, X.; Hong, Y. Using CYGNSS Data to Monitor China's Flood Inundation during Typhoon and Extreme Precipitation Events in 2017. Remote Sens. 2019, 11, 854. [CrossRef]

4. He, K.; Ma, Z.; Zhao, R.; Biswas, A.; Teng, H.; Xu, J.; Yu, W.; Shi, Z. A Methodological Framework to Retrospectively Obtain Downscaled Precipitation Estimates over the Tibetan Plateau. Remote Sens. 2018, 10, 1974. [CrossRef]

5. Ma, Z.; He, K.; Tan, X.; Xu, J.; Fang, W.; He, Y.; Hong, Y. Comparisons of Spatially Downscaling TMPA and IMERG over the Tibetan Plateau. Remote Sens. 2018, 10, 1883. [CrossRef]

6. Trent, T.; Boesch, H.; Somkuti, P.; Scott, A.N. Observing Water Vapour in the Planetary Boundary Layer from the Short-Wave Infrared. Remote Sens. 2018, 10, 1469. [CrossRef]

7. Zhang, F.; Barriot, J.-P.; Xu, G.; Yeh, T.-K. Metrology Assessment of the Accuracy of Precipitable Water Vapor Estimates from GPS Data Acquisition in Tropical Areas: The Tahiti Case. Remote Sens. 2018, 10, 758. [CrossRef]

8. Du, J.; Kimball, S.J.; Reichle, H.R.; Jones, A.L.; Watts, D.J.; Kim, Y. Global Satellite Retrievals of the Near-Surface Atmospheric Vapor Pressure Deficit from AMSR-E and AMSR2. Remote Sens. 2018, 10, 1175. [CrossRef] [PubMed]

9. Silva Oliveira, B.; Caria Moraes, E.; Carrasco-Benavides, M.; Bertani, G.; Augusto Verola Mataveli, G. Improved Albedo Estimates Implemented in the METRIC Model for Modeling Energy Balance Fluxes and Evapotranspiration over Agricultural and Natural Areas in the Brazilian Cerrado. Remote Sens. 2018, 10, 1181. [CrossRef]

10. Panegrossi, G.; Rysman, J.-F.; Casella, D.; Marra, C.A.; Sanò, P.; Kulie, S.M. CloudSat-Based Assessment of GPM Microwave Imager Snowfall Observation Capabilities. Remote Sens. 2017, 9, 1263. [CrossRef]

11. Mohammed, N.I.; Bolten, D.J.; Srinivasan, R.; Lakshmi, V. Improved Hydrological Decision Support System for the Lower Mekong River Basin Using Satellite-Based Earth Observations. Remote Sens. 2018, 10, 885. [CrossRef] [PubMed]

(C) 2019 by the authors. Licensee MDPI, Basel, Switzerland. This article is an open access article distributed under the terms and conditions of the Creative Commons Attribution (CC BY) license (http://creativecommons.org/licenses/by/4.0/). 